Escritura y Pensamiento 20-24(40-48), 2021, 457-461

\title{
Gusmán, Luis. Villa. Buenos Aires: Edhasa, 2020, 278 pp.
}

Uno de los varios imperativos que guían el trabajo editorial de la filial argentina de Edhasa es la tarea de rescatar libros nacionales y extranjeros del pasado que siguen siendo de lectura obligatoria en el presente. Con esta convicción la editorial apuesta a una nueva reedición de Villa ${ }^{1}$ de Luis Gusmán, por motivo del aniversario veinticinco de su publicación. La novela es uno de los primeros experimentos literarios que rescata la voz en primera persona de los eslabones que formaron parte de la gran maquinaria represiva que fue puesta en movimiento en la década del setenta hasta principios de los ochenta por dirigentes políticos pertenecientes al sector de extrema derecha durante el último gobierno constitucional peronista (1973-1976) ${ }^{2}$ y los gobiernos antidemocráticos que se sucedieron durante la Dictadura Militar (1976-1983), para combatir y exterminar a las disidencias ideológicas.

Villa urde su potencia innovadora en un escenario histórico en el que después de los años de violencia y el restablecimiento del gobierno democrático se desarrollaron varios acontecimientos significativos para el campo de las letras y para un país con contradicciones internas en cuanto al proceso de construcción de una memoria sobre el pasado reciente y las luchas por Justicia y Verdad. Algunos de esos acontecimientos que hacen eco en la novela y que el lector debe leer entrelineas son la publicación del Nunca Más: Informe final de la Comisión Nacional sobre la desaparición de las personas (1984) que reivindica y rescata jurídica, política y simbólicamente a las víctimas de la repre- 
sión estatal, primando el testimonio de los sobrevivientes y los familiares de los desaparecidos por sobre el de los represores; el juicio de los dirigentes de las Juntas Militares $(1985)^{3}$ en donde la sociedad argentina tampoco pudo escuchar la palabra de los acusados debido a las restricciones impuestas a los medios de comunicación (Eliaschev, 2011) ${ }^{4}$; la sanción de las denominadas "leyes y decretos de impunidad", entre 1986 y 19905; y la publicación de El Vuelo (1995) del periodista Horacio Verbitsky, que recupera las confesiones del capitán de corbeta Adolfo Scilingo sobre su participación en los "vuelos de la muerte".

A contrapelo del género testimonial privilegiado por los autores en la primera década de posdictadura, Luis Gusmán apuesta por lo puramente ficcional, haciendo que el protagonista de la novela, un funcionario de gobierno que trabaja en el Ministerio de Bienestar Social conducido por José López Rega, elabore un relato sobre sus días en aquella institución antes y en los inicios del Proceso de Reorganización Nacional. ¿Para qué? En la historia, Villa comienza a escribir un informe luego de que participa de ciertas acciones ilegales al servicio de Cummins y Mujica, funcionarios de la Triple A. En él documenta en detalle lo que ocurre en las oficinas y formula una justificación de su relación con esos sujetos, para que ante cualquier eventualidad (cambio socio-político) pueda asegurar su permanencia en el trabajo. Aunque este hecho es bastante esclarecedor, si afinamos la mirada nos encontramos con un relato que va hacia los primeros delineamientos o inicios de la época de terror y con un personaje que mediante la narración, pretende comprender y tratar de explicar el inicio de las acciones políticas represivas y su participación en ellas.

En el prólogo a esta edición, Jorge Panesi emplea la metáfora de la "máquina burocrática estatal" para leer el mundo subterráneo que sostiene la realidad que Villa narra. Cuando este engranaje anónimo, jerárquico y autosuficiente deja de funcionar para el bien común y genera alianzas con la ilegalidad, no es percibido (o no quiere ser percibido) por los sujetos que la vi- 
ven y contribuyen en su funcionamiento: "Con Salinas retornaron los custodios (...) las Itakas y las cuarenta y cinco volvieron a aparecer ante la mirada impávida de los empleados, que otra vez tuvimos que acostumbrarnos mansamente a esos objetos que por un tiempo habían estado fuera de nuestra vida y de nuestra circulación” (Gusmán, 2020, p. 106). La comunicación necesaria y permanente entre el ejército, la policía, la justicia, las áreas de salud e incluso los servicios funerarios conforman para el narrador y sus pares un panorama cotidiano en el que ningún tipo de variación puede perturbar el orden aparente al que están acostumbrados, y las sospechas, siempre presentes, se pierden en su ligereza. Muchos se aferran a la comodidad que otorga estar en un lugar de poder a pesar de que esto los lleve a participar en graves violaciones a las ordenanzas de la Carta Magna argentina. Así, la novela deja en evidencia la perversión de las personas en concordancia con las contradicciones y la corrupción de las instituciones.

Ni víctima ni cómplice, ni represor ni cobarde, más bien un poco de todos, Carlos Villa representa a los sujetos que se ubican en los márgenes de la gran maquinaria represiva. Contradice el sistema de figuras acabadas y contrapuestas (buenos, malos, víctimas, victimarios, etc.) construidas por el Nunca Más (Nofal, 2010) y se esboza a sí mismo como un involucrado o arrastrado: "yo era una hoja en la tormenta, una hoja arrastrada por el viento" (2020, p. 174), pero no por eso menos responsable de la desaparición de Elena, su amor de juventud. En este sentido, estamos ante un personaje complejo y clave, quien aunque siendo un subalterno detenta poder sobre espacios que trascienden lo íntimo, pues en su cargo de médico del Ministerio puede decidir sobre la vida de los demás y las condiciones en que estos mueren: "Usted mismo, Villa, puede mover un avión. Supongamos que está en la guardia, Villalba no está, Salinas se fue de viaje y el Equipo Médico está volando en otro lado y usted tiene que decidir mover un avión. Da las 
instrucciones y todo un mecanismo se pone en movimiento" (2020, pp. 159- 160).

$\mathrm{Si}$ en su oficio de "mosca" revolotea alrededor de un grande, en el mundo maquínico del que forma parte trama relaciones con quien la situación lo amerita, formando de este modo una red de varias lealtades. Su permanencia en el lugar de poder que ocupa se sostiene por esos vínculos, pero también son ellos los que pueden determinar su caída. Por ese lugar naturaliza hechos que son inadmisibles y toma distancia de acontecimientos sociales cercanos a lo popular y, a su vez, ligados a su historia personal de juventud e infancia, porque previo a sus merodeos en el Ministerio y a su intervención en "la tormenta" Villa tuvo una niñez y adolescencia modesta con la tía Elisa en el barrio los Olímpicos, una amistad con el Polaco y un noviazgo con Elena. Dado esto, antes que formular juicios la novela nos devela escenas - acotadas por la experiencia del protagonista-, cuyos sentidos deben buscarse en la concatenación de los acontecimientos y los recovecos biográficos, pues lo intrigante y conflictivo de la historia emerge en este contrapunto que, sin supeditarnos la lectura, nos recuerda a Eichmann en Jerusalén (1963) de Hannah Arendt.

Villa es una propuesta literaria que incomoda y hace trastabillar las nociones, figuras e ideas construidas acerca de los años de violencia estatal (iniciada con el lópezrreguismo y potenciada en la dictadura) y los agentes que la perpetraron directa o indirectamente. Contradictoria al panorama de finales de los ochenta y principios de los noventa, de un modo sutil, la novela nos interpela sobre los alcances y la pertinencia de la obediencia debida y su poder justificador. Con o sin un afán de resistir a las pretensiones de vuelta de página y desmemoria, constituye una nueva modulación de la narrativa argentina de posdictadura, pues recupera la voz y la experiencia de los que revolotean alrededor de la maquinaria represiva, ampliando el paradigma de perspectivas. Es una novela que indudablemente merece ser revisitada, sobre todo en un contexto en el que 
están emergiendo miradas y propuestas inéditas que se interrogan y generan nuevos sentidos sobre el pasado, tal como la publicación reciente del libro Escritos desobedientes (2018) del colectivo de hijas, hijos y familiares de genocidas Historias Desobedientes. Coincidencias que lejos de ser azarosas son el punto de partida necesario para la apertura de un itinerario de lecturas de textos que abordan el tema de la memoria y los procesos históricos de violencia, sin exclusiones ni prejuicios. (Evelyn Inés Zerpa)

\section{Notas}

1 La editorial edita la novela por primera vez en el año 2006.

2 Esta maquinaria fue institucionalizada a partir de la creación de la organización paramilitar conocida como la Triple A (Alianza Anticomunista Argentina) durante la gestión de José López Rega en el Ministerio de Bienestar Social. Aunque su funcionamiento duró pocos años — de 1973 a 1975—, es un antecedente importante de las actividades delictivas y violatorias de los Derechos Humanos que caracterizó a la última dictadura.

3 Jorge Rafael Videla (Comandante en del Ejército entre 1976 y 1978), Eduardo Emilio Massera (Comandante en jefe de la Armada entre 1976 y 1978) y Orlando Ramón Agosti (Comandante en jefe de la Fuerza Aérea, entre 1978 y 1978) conformaron la primera juna militar entre 1976 y 1980. Roberto Eduardo Viola (Comandante en del Ejército entre 1978 y 1979), Armando Lambruschini (Comandante en jefe de la Armada entre 1978 y 1981) y Omar Domingo Rubens Graffigna (Comandante en jefe de la Fuerza Aérea, entre 1978 y 1979) formaron parte de la segunda junta militar entre 1980 y 1981. Leopoldo Fortunato Galtieri (Comandante en del Ejército entre 1979 y 1982, Jorge Isaac Anaya [Comandante en jefe de la Armada entre 1981 y 1982] y Basilio Lami Dozo [Comandante en jefe de la Fuerza Aérea, entre 1979 y 1982], integraron la tercera junta entre 1981 y 1982).

4 Eliaschev, Pepe (2011) Los hombres del juicio. Por primera vez los jueces y el fiscal que condenaron a los ex comandantes cuentan la historia intima del acontecimiento que cambió a la Argentina para siempre. Buenos Aires: Editorial Sudamericana S.A.

5 La Ley del Punto Final (1986), la Ley de la Obediencia Debida (1987) y los indultos a civiles y militares condenados por crímenes de lesa humanidad durante la última dictadura, realizados durante la presidencia de Carlos Menem, en los años 1989 y 1990. 